\title{
Curcumin increases the sensitivity of K562/DOX cells to doxorubicin by targeting S100 calcium-binding protein A8 and P-glycoprotein
}

\author{
LIU YANG ${ }^{1,2 *}$, DUO LI $^{3 *}$, PEIYAN TANG ${ }^{3}$ and YUNFEI ZUO ${ }^{1,2}$ \\ ${ }^{1}$ Center for Post-doctoral Research; ${ }^{2}$ Department of Clinical Biochemistry, School of Laboratory Medicine; \\ ${ }^{3}$ College of Stomatology, Dalian Medical University, Dalian, Liaoning 116044, P.R. China
}

Received September 25, 2018; Accepted June 4, 2019

DOI: $10.3892 / 01.2019 .11083$

\begin{abstract}
The development of multidrug resistance (MDR) has seriously impeded the efficacy of drug treatment of chronic myeloid leukemia (CML). Recent studies have indicated that S100 calcium-binding protein A8 (S100A8) is associated with the occurrence and development of MDR. Traditional Chinese medicine may provide drugs with the potential to be used as multidrug resistance reversal agents with low toxicity and multi-target characteristics. The present study selected K562/DOX cells, a CML drug-resistant cell line, as a research model, and aimed to examine whether curcumin was able to reverse the resistance to doxorubicin (DOX), and elucidate the underlying molecular mechanisms. An MTT cytotoxicity assay indicated that curcumin at $0.5-2 \mu \mathrm{M}$ reversed DOX resistance with a reversal index of 1.3-9.3. Western blot analysis revealed that curcumin treatment caused a downregulation of the expression of P-glycoprotein (P-gp) and S100A8 in a dose- and time-dependent manner. To study the internal association between S100A8 and P-gp, and the S100A8 role in drug resistance reversal, an RNA knockdown assay was conducted; however, S100A8 did not regulate the expression of P-gp or vice versa. After inhibiting the expression of S100A8 with specific small interfering RNA (si-S100A8), the sensitivity of
\end{abstract}

Correspondence to: Professor Yunfei Zuo, Department of Clinical Biochemistry, School of Laboratory Medicine, Dalian Medical University, 9 West Section, Lvshun South Road, Lvshunkou, Dalian, Liaoning 116044, P.R. China

E-mail: zuoyunfei_dy@163.com

${ }^{*}$ Contributed equally

Abbreviations: DOX, doxorubicin; K562/DOX, DOX-resistant K562 cell line; S100A8, S100 calcium-binding protein A8; Bcl-xL, B-cell lymphoma extra-large; Bax, Bcl-2-associated X protein; CHOP, CCAAT/enhancer-binding protein homologous protein; si-S100A8, small interfering RNA targeting S100A8

Key words: chronic myeloid leukemia, S100 calcium-binding protein A8, P-glycoprotein, doxorubicin, multidrug resistance
K562/DOX cells to DOX was enhanced. In addition, si-S100A8 did not increase the intracellular accumulation of DOX, but increased the intracellular free calcium ion content, and the expression and activity of apoptosis-associated proteins, thereby inducing apoptosis. In conclusion, the present study suggested that inhibition of S100A8 expression increased DOX-induced apoptosis, and curcumin acted independently on S100A8 and P-gp to exert its drug resistance reversal effects

\section{Introduction}

Leukemia is a type of hematological disease characterized by the malignant proliferation of leukocytes. It is mainly divided into chronic lymphocytic leukemia, chronic myeloid leukemia (CML), acute lymphoblastic leukemia and acute myeloid leukemia (1). The treatment of leukemia has always been based on chemotherapy; however, multidrug resistance (MDR) that occurs during chemotherapy has seriously impeded the efficacy of leukemia treatment $(2,3)$. Based on extensive research, the mechanisms of the MDR of leukemia are mainly divided into the following categories: i) Overexpression of transporters; ii) evasion of apoptosis-associated signaling pathways; and iii) changes in the intracellular microenvironment, all of which lead to an increase in the tolerance of cells to chemotherapeutic drugs $(2,4)$. The MDR phenomenon of leukemia cells is widespread, and its mechanisms are diverse (5). Therefore, seeking reversal strategies or reversal agents to overcome MDR has become a research hotspot (6). Chemical reversal agents usually have serious toxicity and side effects; for instance, verapamil (VRP) and cyclosporin A, which target p-glycoprotein (P-gp), although producing good reversal effects in vitro, cannot be applied in a clinical setting due to their serious toxic side effects. Furthermore, they only have a single mechanism of action and poor selectivity (7).

Traditional Chinese medicine has a long history and abundant resources, and it provides a large number of drugs targeting multiple factors and pathways (8). An increasing amount of research has been conducted regarding potential MDR reversal agents for leukemia (9). Curcumin (Fig. 1A) is a polyphenolic compound extracted from the rhizome of Zingiberaceae and Araceae, and has numerous biological effects with pharmaceutical applications, including analgesic, 
antioxidant, anti-inflammatory, antiseptic, antirheumatic and antiatherosclerotic actions. Due to its multiple actions and multi-targeting characteristics, curcumin has attracted widespread attention (10). Previous studies have indicated curcumin's antitumor activity $(11,12)$. An early study indicated that curcumin modulates the function and expression of P-gp in vitro, potentially sensitizing $\mathrm{P}$-gp-overexpressing cell lines to chemotherapeutics (13). A large number of subsequent studies have also supported this hypothesis $(14,15)$; however, the majority of studies on curcumin have primarily focused on its effects on the function and expression of P-gp (16). Due to its multiple targets, curcumin may possess further molecular mechanisms that are worth examining within the context of MDR.

The S100 proteins are a family of low molecular weight (9-13 kDa) calcium-binding proteins featuring an EF-hand structure with 21 members, and are widely distributed in various types of tissue, such as brain, heart, kidneys and skin, and is highly expressed in the brain and heart $(17,18)$. Upon binding to calcium ions, the conformation of the protein changes, exposing its binding site to the target protein, and thereby exerting its biological effects via the corresponding target protein (19). Therefore, S100 protein is considered to be a calcium sensor protein, which has an important role in cell proliferation, differentiation, muscle contraction, gene expression, secretion and apoptosis through the calcium signal transduction pathway. S100 calcium-binding protein A8 (S100A8), also known as myeloid-related protein 8 or calgranulin A, is a member of the $\mathrm{S} 100$ multigene subfamilies. Studies have indicated that S100A8 is associated with the progression of multiple tumor types and mediates apoptosis through the B-cell lymphoma 2 (Bcl-2) family of proteins $(20,21)$. Recent studies have also shown that S100A8 is associated with drug resistance $(22,23)$. The present study examined two possible targets, P-gp and S100A8, to elucidate the mechanisms via which curcumin reverses the drug resistance of doxorubicin (DOX)-resistant K562 (K562/DOX) cells. The study aimed to provide a sufficient basis for the clinical application of curcumin to improve the efficacy of chemotherapy for drug-resistant leukemia.

\section{Materials and methods}

Cell culture. The human CML cell lines K562 and K562/DOX were obtained from Nanjing KeyGen Biotech Co., Ltd. Cells were cultured in RPMI-1640 medium (Gibco; Thermo Fisher Scientific, Inc.) supplemented with $100 \mathrm{U} / \mathrm{ml}$ penicillin/streptomycin and $10 \%$ fetal calf serum (Gibco; Thermo Fisher Scientific, Inc.) at $37^{\circ} \mathrm{C}$ with $5 \% \mathrm{CO}_{2}$. and passaged every 2-3 days to maintain logarithmic growth. In order to maintain DOX resistance, K562/DOX cells were cultured in medium with $2 \mathrm{mg} / \mathrm{ml}$ DOX (Sigma-Aldrich; Merck KGaA). K562/DOX cells were grown in DOX-free culture medium for $>2$ weeks prior to the assays.

MTT assay. K562 or K562/DOX cells were seeded in 96-well plates at a density of 5,000 cells/well. After $24 \mathrm{~h}$, cells were incubated with various drugs. The concentration of DOX was $0,0.8,1.6,3.13,6.25,12.5,25,50 \mu \mathrm{M}$ and the concentration of curcumin used was $0,0.5,1,2,4,8,16,32 \mu \mathrm{M}$. The MTT assay was then performed according to the manufacturer's protocol (BioVision, Inc.). The absorbance was measured at a wavelength of $570 \mathrm{~nm}$ using a microplate reader (Bio-Rad Laboratories, Inc.). The $\mathrm{IC}_{50}$ value was calculated with SPSS 23.0 (IBM Corp.). Resistance Index was calculated by dividing the $\mathrm{IC}_{50}$ values of $\mathrm{K} 562 / \mathrm{DOX}$ cells in the presence or absence of curcumin by the $\mathrm{IC}_{50}$ values of $\mathrm{K} 562$ cells without curcumin. Reversal Index was calculated by dividing the values of Resistance Index without curcumin by the Resistance Index in the presence or absence of curcumin.

Western blot analysis. A total of $1 \times 10^{6}$ K562 or K562/DOX cells were collected, washed thrice with ice-cold PBS and lysed with ice-cold RIPA lysis buffer (Beyotime Institute of Biotechnology). The protein content was detected using the BCA protein concentration determination kit (cat. no. PC0020; Beijing Solarbio Science \& Technology Co., Ltd.). A total of $30 \mu \mathrm{g}$ protein was loaded per lane and subjected to SDS-PAGE (upper gel 5\%, separation gel 10-15\%). The nitrocellulose membranes were blocked by 5\% BSA blocking buffer for $1 \mathrm{~h}$ at room temperature and incubated with primary antibodies overnight at $4^{\circ} \mathrm{C}$ after washing three times with $0.1 \%$ Tween-20 in Tris-buffered saline; membranes were then incubated with alkaline phosphatase-conjugated anti-rabbit (cat. no. 7054; 1:5,000 dilution) or mouse (cat. no. 7056; 1:5,000 dilution) antibodies (Cell Signaling Technology, Inc.) for $1 \mathrm{~h}$ at room temperature, and then developed with enhanced chemiluminescence reagent (Beyotime Institute of Biotechnology). Band density was quantified using ImageJ software 1.46r (National Institutes of Health). Antibodies against P-gp (cat. no. 13342; 1:1,500 dilution) and CCAAT/enhancer-binding protein homologous protein (CHOP; cat. no. 2895; 1:2,000 dilution) were obtained from Cell Signaling Technology, Inc.; anti-S100A8 antibody (cat. no. 15792-1-AP; 1:1,500 dilution) was obtained from ProteinTech Group, Inc., whereas antibodies specific for Bcl extra-large (Bcl-xL; cat. no. bs-5234R; 1:1,000 dilution), Bcl-2-associated X protein (Bax; cat. no. bs-0127R; 1:1,000 dilution) and $\beta$-actin (cat. no. bs-0061R; 1:1,000 dilution) were purchased from Bioss Antibodies.

Determination of intracellular rhodamine (RHO)-123 retention. Intracellular retention of RHO-123 (Beyotime Institute of Biotechnology) was detected in order to determine P-gp efflux function (24). K562 or K562/DOX Cells were seeded in 6-well plates at $5 \times 10^{5}$ cells/well. The cells were pre-treated with the indicated drugs (VRP $10 \mu \mathrm{M}$; curcumin $0.5,1$ and $2 \mu \mathrm{M}$ ) for $48 \mathrm{~h}$ at $37^{\circ} \mathrm{C}$ with $5 \% \mathrm{CO}_{2}$ and subsequently $\operatorname{VRP}(10 \mu \mathrm{M})$ was used as a positive control. After pre-treatment, the cells were incubated with $10 \mu \mathrm{g} / \mathrm{ml}$ RHO-123 in RPMI-1640 medium at $37^{\circ} \mathrm{C}$ for $45 \mathrm{~min}$. The cells were then collected, washed with ice-cold PBS twice and suspended in $0.5 \mathrm{ml}$ RPMI-1640 medium. The mean fluorescence intensity of the samples was determined via flow cytometric analysis (FACSCalibur ${ }^{\mathrm{TM}}$; BD Biosciences) using a 530-nm long band-pass filter. The data of flow cytometric was analyzed by FlowJo X 10.0.7r2 (FlowJo, LLC).

Intracellular accumulation of DOX. The intracellular accumulation of DOX was examined by measuring the fluorescence intensity of DOX. The K562 or K562/DOX cells were seeded 


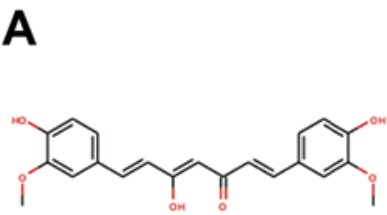

Curcumin
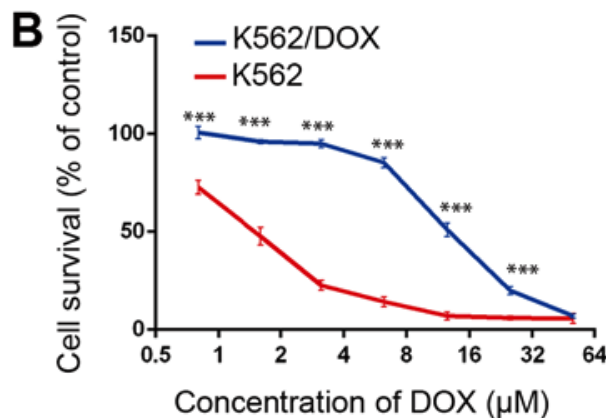
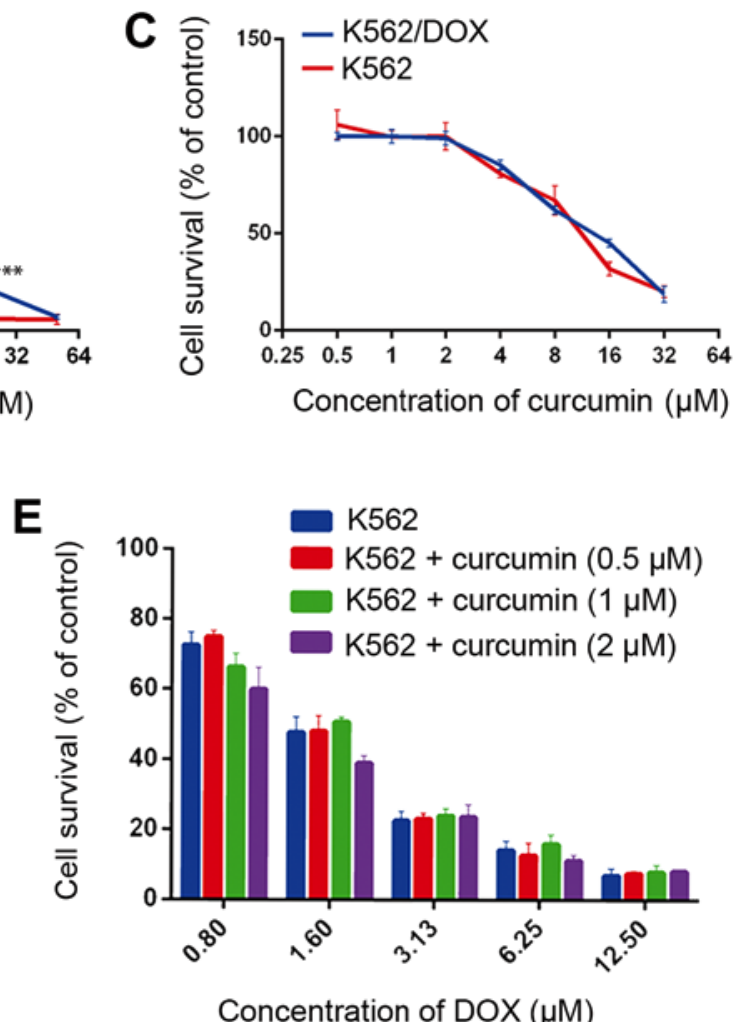

Figure 1. Curcumin enhances the cytotoxicity of in K562/DOX cells. (A) Chemical structure of curcumin. K562 and K562/DOX cells were treated with (B) DOX (0-50 $\mu \mathrm{M})$ and (C) with curcumin (0-32 $\mu \mathrm{M})$ for $48 \mathrm{~h}$. (D) K562/DOX and (E) K562 cells were pre-treated with curcumin (0.5, 1 and $2 \mu \mathrm{M})$ for $24 \mathrm{~h}$, followed by incubation with various concentrations of DOX for an additional $48 \mathrm{~h} .{ }^{* * *} \mathrm{P}<0.001 \mathrm{vs}$. the control group (not treated with curcumin). DOX, doxorubicin; K562/DOX, DOX-resistant K562 cell line; S100A8, S100 calcium-binding protein A8.

in 6-well plates at $5 \times 10^{5}$ cells/well. After $24 \mathrm{~h}$, the cells were pre-treated for $48 \mathrm{~h}$ at $37^{\circ} \mathrm{C}$ with $5 \% \mathrm{CO}_{2}$ and then $2 \mathrm{ml} \mathrm{DOX}$ $(4 \mu \mathrm{M})$ was added to each well, followed by incubation at $37^{\circ} \mathrm{C}$ for $60 \mathrm{~min}$ in the dark. Following incubation, the cells were immediately washed with ice-cold PBS three times and lysed with RIPA lysis buffer, and the fluorescent signal of the cells was detected with a multimode microplate reader (TriStar2; Berthold Bio) using a 595-nm long band-pass filter.

Apoptosis detection assay. Caspase-3 activity was detected with a caspase-3 activity assay kit (cat. no. BC3830; Beijing Solarbio Science \& Technology Co., Ltd.) (25). In brief, $5 \times 10^{6}$ pre-treated K562 or K562/DOX cells were collected and lysed. After centrifugation at $4^{\circ} \mathrm{C}$ at $12,000 \mathrm{x} \mathrm{g}$ for $10 \mathrm{~min}$, the supernatant was collected and according to the manufacturer's protocol, the corresponding reagent was added. The absorbance was measured at a wavelength of $405 \mathrm{~nm}$ using a microplate reader (Bio-Rad Laboratories, Inc.). The caspase-3 activity was quantified as the absorbance of the drug-treated cells relative to that of the vehicle-treated control cells.

The stage of apoptosis was analyzed by staining with DAPI (cat. no. C1002; Beyotime Institute of Biotechnology) as described previously (26). DAPI can be used for the detection of apoptosis, because it is a blue fluorescent dye that can penetrate cell membranes. Binding to double-stranded DNA produces a $>20$-fold increase in fluorescence compared with DAPI itself (27). According to the recommended DAPI concentration of $0.5-10 \mu \mathrm{g} / \mathrm{ml}$, a final concentration of $5 \mu \mathrm{g} / \mathrm{ml}$ was selected (28). The cells were seeded in 6-well plates at $5 \times 10^{5}$ cells/well and subjected to the designated treatments for $48 \mathrm{~h}$, and subsequently, $0.5 \mathrm{ml}$ DAPI at a final concentration of $5 \mu \mathrm{g} / \mathrm{ml}$ was added to each well, followed by incubation at $37^{\circ} \mathrm{C}$ for $30 \mathrm{~min}$ in the dark. The cells were then immediately washed with ice-cold PBS and observed under an inverted fluorescence microscope (magnification, x100; OIS IX81; Olympus Corporation) using a 454-nm long band-pass filter.

Determination of the intracellular concentration of $\mathrm{Ca}^{2+}$. For calcium determination, $5 \times 10^{5} \mathrm{~K} 562$ or K562/DOX cells that had been subjected to the aforementioned treatments were collected and lysed with lysis buffer. A Calcium Colorimetric Assay kit (cat. no. MAK022; Sigma-Aldrich; Merck KGaA) was used to analyze the intracellular calcium ion concentration, according to the manufacturer's protocol. The absorbance was measured at a wavelength of $575 \mathrm{~nm}$ using a microplate reader (Bio-Rad Laboratories, Inc.).

RNA knockdown. Small interfering (si)RNA oligos for P-gp and S100A8, and no-targeting si-RNA controls (ctrl) for S100A8 and P-gp were synthesized by General Biosystems, Inc. For knockdown experiments, siRNA oligos were diluted to a concentration of $50 \mathrm{nM}$ and transfected into the cells with Lipofectamine $^{\mathrm{TM}} 2000$ (Invitrogen; Thermo Fisher Scientific, Inc.), according to the manufacturer's protocol. The sequences for P-gp siRNA and sictrl P-gp were as follows: P-gp siRNA, forward, 5'-CGGAAGGCCUAAUGCCGAA-3' and reverse, 5'-UUCGGCAUUAGGCCUUCCG-3'; sictrl P-gp, 
Table I. $\mathrm{IC}_{50}$ values and reversal effect of curcumin on DOX in K562 and K562/DOX cells.

\begin{tabular}{|c|c|c|c|c|}
\hline \multirow[b]{2}{*}{ Drugs } & \multicolumn{2}{|c|}{$\mathrm{IC}_{50} \pm$ standard deviation $^{\mathrm{a}}(\mu \mathrm{M})$} & \multirow[b]{2}{*}{ Reversal index } & \multirow[b]{2}{*}{ Resistance index } \\
\hline & K562 & K562/DOX & & \\
\hline DOX & $1.38 \pm 0.22$ & $13.83 \pm 4.43^{\mathrm{c}}$ & 10 & 1 \\
\hline Curcumin $^{\mathrm{b}}$ & $2.3 \pm 0.17\left(\mathrm{IC}_{10}\right)$ & $2.5 \pm 0.24\left(\mathrm{IC}_{10}\right)$ & I & l \\
\hline $\mathrm{DOX}+\operatorname{curcumin}(0.5 \mu \mathrm{M})$ & $1.4 \pm 0.28$ & $10.91 \pm 2.84^{\mathrm{c}}$ & 7.9 & 1.3 \\
\hline $\mathrm{DOX}+\operatorname{curcumin}(1 \mu \mathrm{M})$ & $1.373 \pm 0.18$ & $5.72 \pm 0.83^{\mathrm{c}}$ & 4.1 & 2.43 \\
\hline $\mathrm{DOX}+\operatorname{curcumin}(2 \mu \mathrm{M})$ & $1.052+0.24$ & $1.48 \pm 0.13^{\mathrm{c}}$ & 1.07 & 9.3 \\
\hline
\end{tabular}

${ }^{\mathrm{a}} \mathrm{IC}_{50}$ or $\mathrm{IC}_{10}$ values represent the mean \pm standard deviation of three independent experiments performed in triplicate. ${ }^{\mathrm{b}} \mathrm{Curcumin} \mathrm{IC}_{10} \mathrm{values}^{\mathrm{a}}$ were calculated to choose the non-toxic concentration. ${ }^{c} \mathrm{P}<0.01$ vs. DOX. DOX, doxorubicin; K562/DOX, DOX-resistant K562 cell line.

A

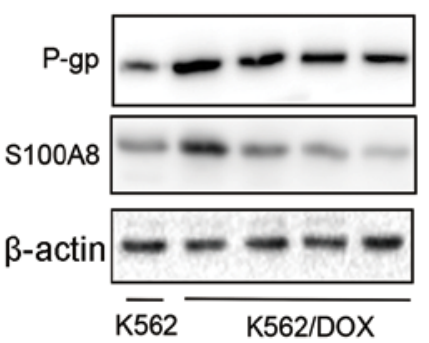

Curcumin $(\mu \mathrm{M})-\quad-0.5 \quad 1 \quad 2$

D

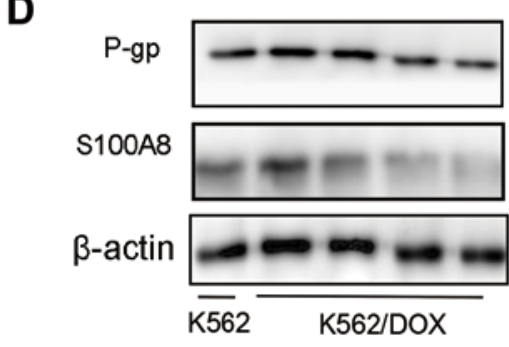

B

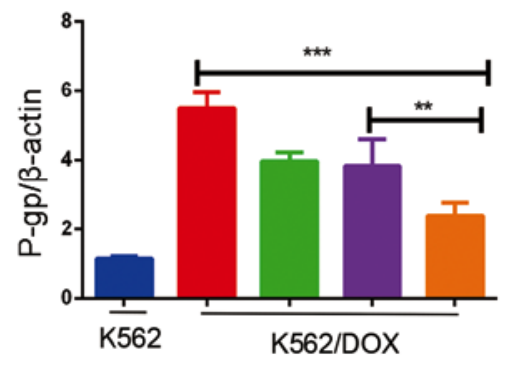

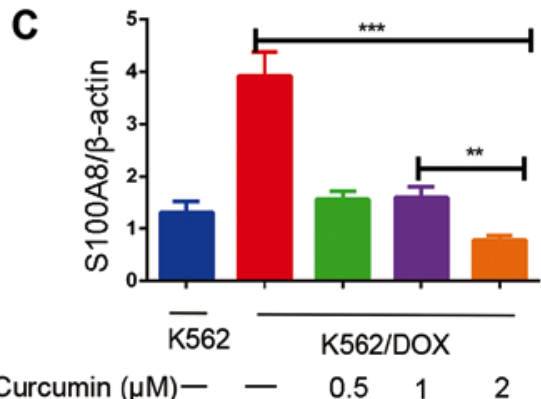

E

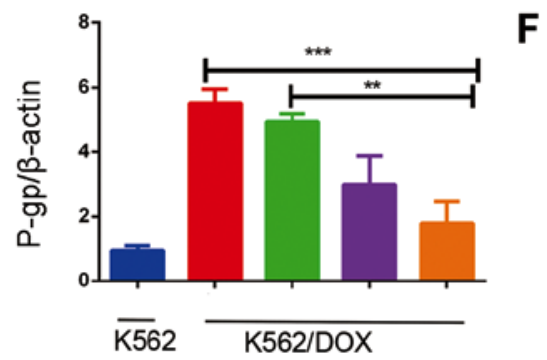

$\mathbf{F}$

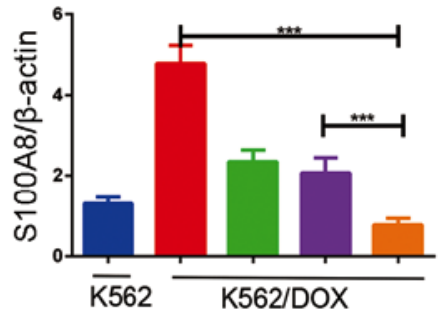

Curcumin $(2 \mu \mathrm{M})--24 \mathrm{~h} 48 \mathrm{~h} 72 \mathrm{~h} \mathrm{Curcumin}(2 \mu \mathrm{M})--24 \mathrm{~h} 48 \mathrm{~h} 72 \mathrm{~h}$ Curcumin $(2 \mu \mathrm{M})-\mathrm{C}-24 \mathrm{~h} 48 \mathrm{~h} 72 \mathrm{~h}$

Figure 2. Curcumin downregulates P-gp and S100A8 protein expression in K562/DOX cells. (A) K562/DOX cells were treated with curcumin (0.5, 1 or $2 \mu \mathrm{M})$ for $48 \mathrm{~h}$, and western blot analysis was performed to detect the protein expression levels of (B) P-gp and (C) S100A8. (D) K562/DOX cells were treated with curcumin $(2 \mu \mathrm{M})$ for 24,48 or $72 \mathrm{~h}$, followed by western blot analysis of (E) P-gp and (F) S100A8 protein expression. ${ }^{* *} \mathrm{P}<0.01,{ }^{* * *} \mathrm{P}<0.001$. DOX, doxorubicin; K562/DOX, DOX-resistant K562 cell line; S100A8, S100 calcium-binding protein A8; P-gp, P-glycoprotein.

forward, 5'-UGUAGAUGGACUUGAACUC-3', and reverse, 5'-GAGUUCAAGUCCAUCUACA3' (29). The following sequences were used for S100A8 siRNA and sictrl S100A8: S100A8 siRNA, forward, 5'-AGACCGAGUGUCCUCAGUA-3' and reverse, 5'-UACUGAGGACACUCGGUCU-3'; sictrl S100A8, forward, 5'-GCGACGAUCUGCCUAAGAU-3' and reverse, 5'-AUCUUAGGCAGAUCGUCGC-3' (30). The K562/DOX cells were treated with different concentrations of drugs. After $48 \mathrm{~h}$ the non-transfection group cells were treated with $4 \mu \mathrm{M}$ DOX, $2 \mu \mathrm{M}$ curcumin alone, or in combination for $48 \mathrm{~h}$, and the transfection group cells were treated with $4 \mu \mathrm{M}$ DOX for $48 \mathrm{~h}$.

Statistical analysis. Values are expressed as the mean \pm standard deviation. Statistical significance between groups was evaluated with a two-tailed Student's t-test using
GraphPad Prism 7 (GraphPad Software, Inc.) and SPSS 23.0 (IBM Corp.). Multiple comparison between the groups was performed using one-way analysis of variance with Student-Newman-Keuls method post hoc test. $\mathrm{P}<0.05$ was considered to indicate a statistically significant difference.

\section{Results}

Curcumin sensitizes K562/DOX cells to DOX. To investigate the sensitization effect of curcumin, an MTT cytotoxicity assay was performed. First the results indicated that the resistant K562/DOX cell line exhibited significant drug resistance to DOX compared with the native K562 cell line, with a resistance index up to 10 (Fig. 1B; Table I). Furthermore, curcumin at 0.5-2 $\mu \mathrm{M}$ was non-toxic to K562 and K562/DOX cells (Fig. 1C; Table I). To determine whether the decrease in 
A

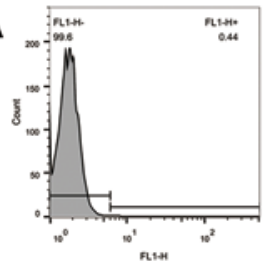

Negative

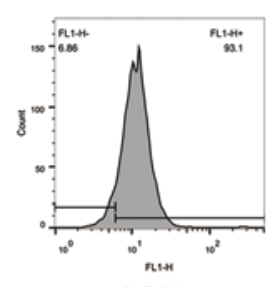

$\mathrm{CON}$

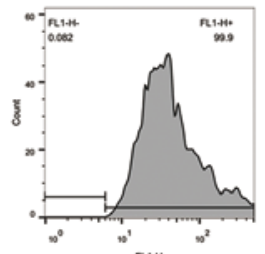

VRP $(10 \mu \mathrm{M})$

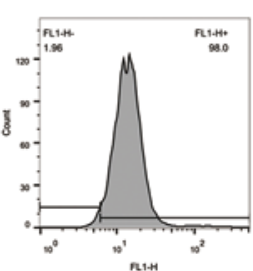

Curcumin $(0.5 \mu \mathrm{M})$

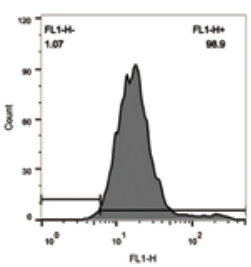

Curcumin $(1 \mu \mathrm{M})$

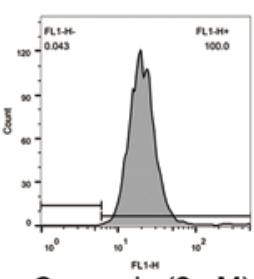

Curcumin $(2 \mu \mathrm{M})$
B

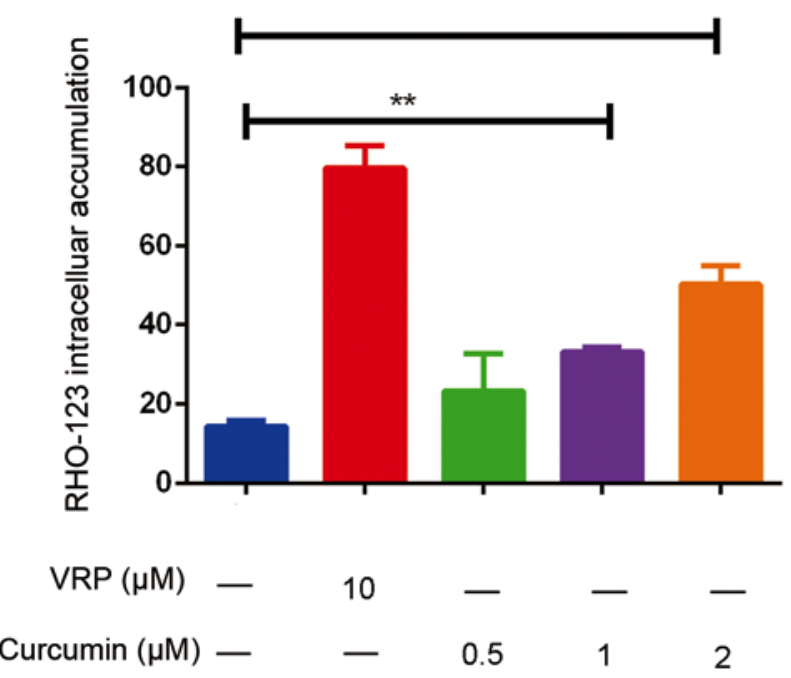

C

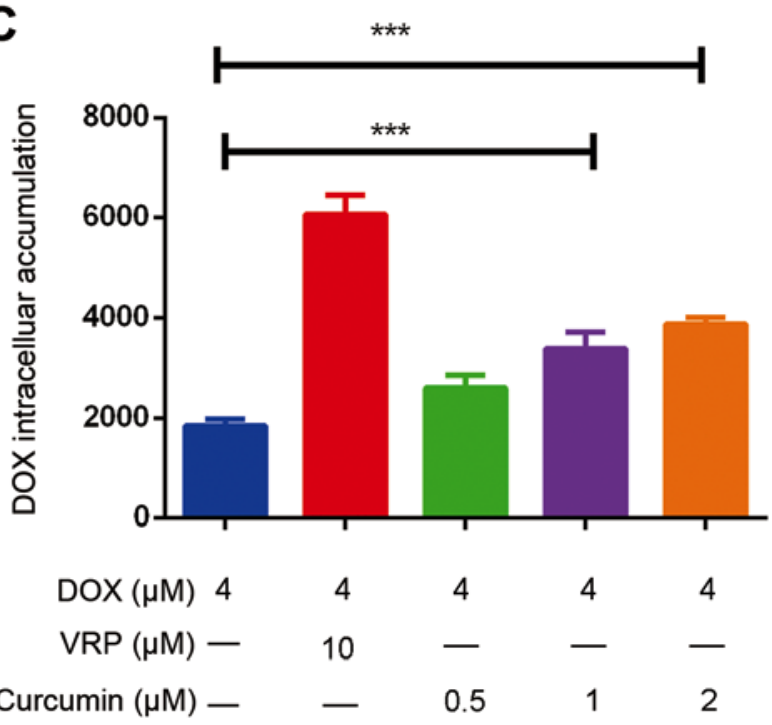

Figure 3. Curcumin increases intracellular accumulation of RHO-123 and DOX in K562/DOX cells. (A) Effects of VRP (10 $\mu \mathrm{M})$ and curcumin (0.5, 1 or $2 \mu \mathrm{M}$ ) on intracellular accumulation of RHO-123 was detected by flow cytometry. 'FL-1H' means RHO-123 emitting light detection channel, X-axis means fluorescence signal was detected by FL-1H. (B) A quantification of the effect of VRP $(10 \mu \mathrm{M})$ and curcumin $(0.5,1$ or $2 \mu \mathrm{M})$ on intracellular accumulation of RHO-123. (C) Effects of VRP (10 Mm) and curcumin $(0.5,1$ or $2 \mathrm{Mm})$ on intracellular accumulation of DOX. ${ }^{* *} \mathrm{P}<0.01,{ }^{* * *} \mathrm{P}<0.001$. DOX, doxorubicin; $\mathrm{VRP}$, verapamil.

the survival rate of K562/DOX and K562 cells was due to the toxicity of curcumin, a non-toxic concentration of curcumin $(0.5,1$ and $2 \mu \mathrm{M})$ was used in combination with DOX. Of note, curcumin significantly enhanced the sensitivity of K562/DOX and cells to DOX. Curcumin reduced the survival rate of K562/DOX at different concentrations of DOX in a dosage-depended manner; the reversal indices of 0.5, 1 and $2 \mu \mathrm{M}$ curcumin were 1.3, 2.43 and 9.3, respectively (Fig. 1D; Table I). However, for the K562 cells, curcumin did not significantly affect the decrease in the cell survival rate caused by DOX (Fig. 1E; Table I). Therefore, it may be concluded that curcumin at non-toxic concentrations reverses the drug resistance of K562/DOX cells.

S100A8 and P-gp are involved in the reversal effects of curcumin on the drug resistance of K562/DOX cells. To investigate the expression of S100A8 and P-gp in K562 and K562/DOX cells, a western blot assay was performed. The results indicated that the expression of S100A8 and P-gp in K562/DOX cells was significantly increased compared with in K562 cells (Fig. 2A and D). The effects of different concentrations of curcumin on the expression of S100A8 and P-gp were then assessed. The results suggested that when curcumin was administered at $0.5,1$ and $2 \mu \mathrm{M}$ for $48 \mathrm{~h}$, the expression levels of S100A8 and P-gp were significantly reduced (Fig. 2A-C). Next, the time-dependence of the effect of curcumin on the downregulation of S100A8 and P-gp in K562/DOX cells was assessed. The results indicated that the expression of P-gp decreased with prolonged incubation with curcumin. The expression of S100A8 following 24 and $48 \mathrm{~h}$ of curcumin treatment was similar, however it was still downregulated compared with that in the control group, and at $72 \mathrm{~h}$, the downregulation effect was most notable (Fig. 2D-F). These results indicated that the dose- and time-dependent downregulation of S100A8 and P-gp expression by curcumin may be associated with its reversal effect on drug resistance. The downregulated expression of P-gp and S100A8 was evident up to the 48-h time point; therefore, the shortest time that induced changes in protein expression, 48-h, was selected for the duration of pre-treatment for subsequent experiments.

Curcumin inhibits the expression and function of $P$-gp, and increases the intracellular accumulation of DOX. The results in Fig. 2 indicated that curcumin treatment causes a decrease in the expression levels of P-gp; it was further investigated whether it inhibits the efflux function of P-gp. To determine this, a RHO-123 assay was performed. The results suggested that curcumin increased the intracellular accumulation of RHO-123 in a dose-dependent manner (Fig. 3A and B). This indicates that the efflux function of $\mathrm{P}$-gp was inhibited when curcumin was administered. In addition, the intracellular accumulation of DOX was assayed; it was revealed that curcumin dose-dependently increased the intracellular accumulation of DOX (Fig. 3C). DOX is a substrate for P-gp (31); however, 


\section{A}

S100A8

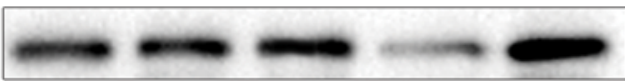

P-gp
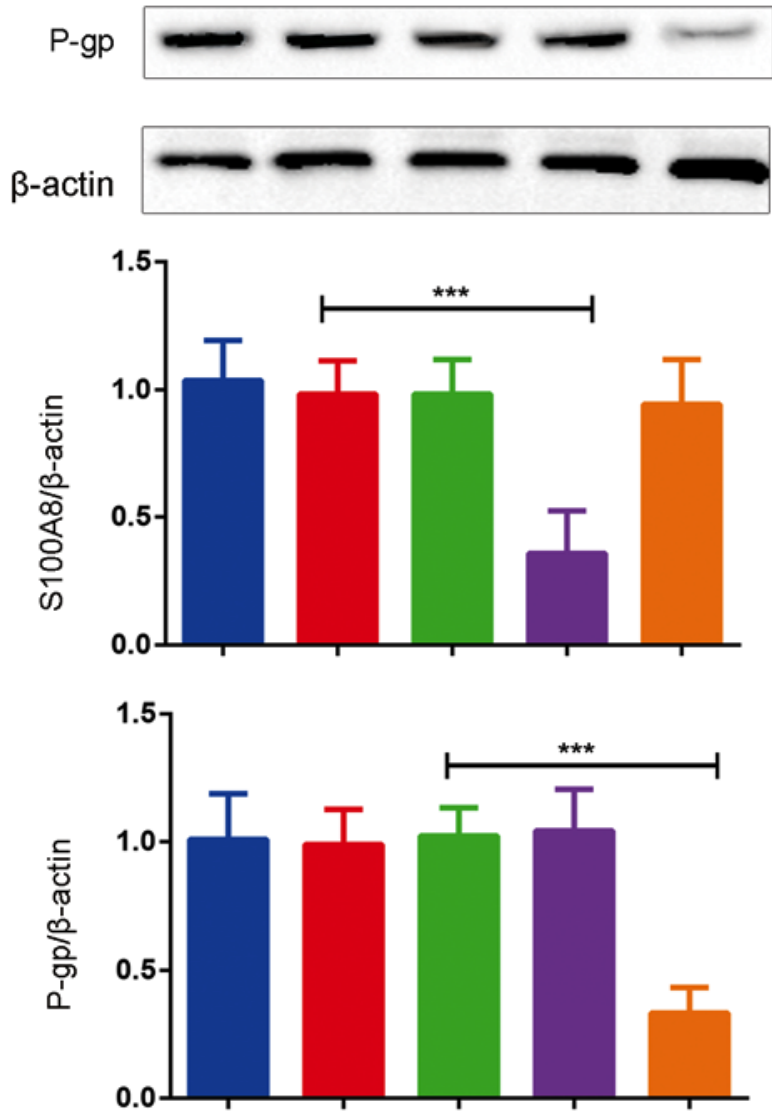

sictrl S100A8 -

$+$

si S100A

sictrl P-gp -

si P-gp
B

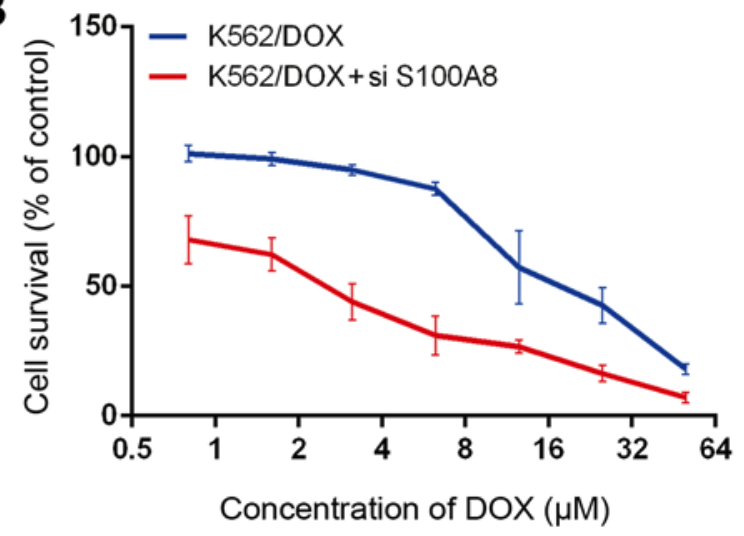

C

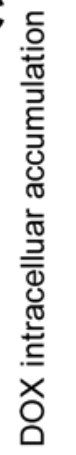

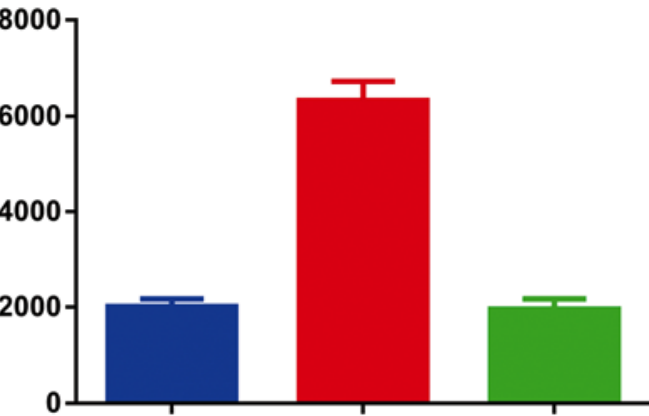

$\operatorname{DOX}(\mu \mathrm{M}) \quad 4$

4

4

$\operatorname{VRP}(\mu \mathrm{M}) \quad-$

10

si S100A8

Figure 4. Silencing of S100A8 increases the sensitivity of K562/DOX cells to DOX, however S100A8 does not affect the expression of P-gp or vice versa. (A) Effects of silencing of S100A8 or P-gp on the protein expression of S100A8 and P-gp. (B) Effects of DOX on the viability of K562/DOX cells after silencing of S100A8. (C) Effects of S100A8-silencing on intracellular accumulation of DOX. ${ }^{* * *} \mathrm{P}<0.001$. DOX, doxorubicin; VRP, verapamil; K562/DOX, DOX-resistant K562 cell line; S100A8, S100 calcium-binding protein A8; si-S100A8, small interfering RNA targeting S100A8; P-gp, P-glycoprotein.

when P-gp is overexpressed, intracellular DOX is transported to the outside of the cell via P-gp, and the resulting intracellular drug concentration becomes too low to induce cancer cell death, thereby producing resistance (32). It is proposed that as curcumin inhibits the expression and function of P-gp, the intracellular drug concentration increases and the drug resistance effect is reversed.

S100A8 and P-gp are involved in the curcumin-induced drug sensitization of K526/DOX cells independent of each other. To elucidate the association between S100A8 and P-gp, gene silencing technology was used. The results indicated that when S100A8 was silenced, the levels of P-gp were not affected, and in turn, gene silencing of P-gp did not affect the expression of S100A8 (Fig. 4A). This result indicated that S100A8 and P-gp mediated curcumin-induced reversal of K526/DOX cell resistance to DOX independent of each other.

In order to further investigate the role of S100A8 in the curcumin-induced reversal of drug resistance, the expression of S100A8 in K562/DOX cells was inhibited by gene silencing, and the sensitivity of K562/DOX to DOX was assessed via a cytotoxicity assay. The results indicated that at the same DOX concentration, the cell survival rate was significantly reduced after silencing S100A8 (Fig. 4B). In addition, the effects of S100A8-knockdown on the intracellular accumulation of DOX were investigated. Of note, after gene silencing of S100A8, the intracellular accumulation of DOX did not significantly increase (Fig. 4C). These results suggest that the role of S100A8 in the curcumin-induced reversal of K562/DOX cell resistance to DOX is not associated with increased intracellular accumulation of DOX.

Curcumin inhibits the expression of S100A8 and increases apoptosis induced by endoplasmic reticulum stress (ERS). S100A8 is a calcium ion-binding protein, and calcium ions are involved in the transduction of various intracellular signaling pathways, such as Ras/ERK/CREB pathway (33-35). The ER is a calcium reservoir in the cell that is sensitive to changes 
A

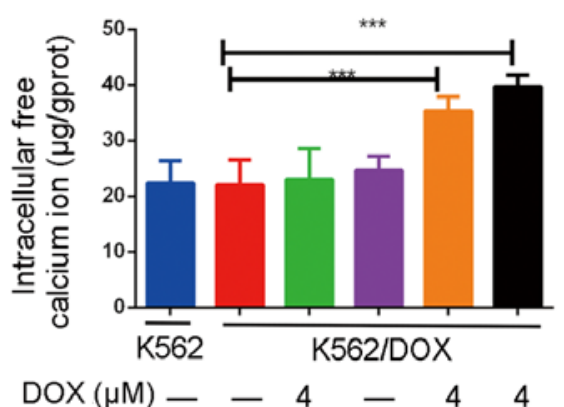

si S100A8 - $-\quad-\quad-\quad \begin{array}{llll}4 & - & 4 & 4\end{array}$
B
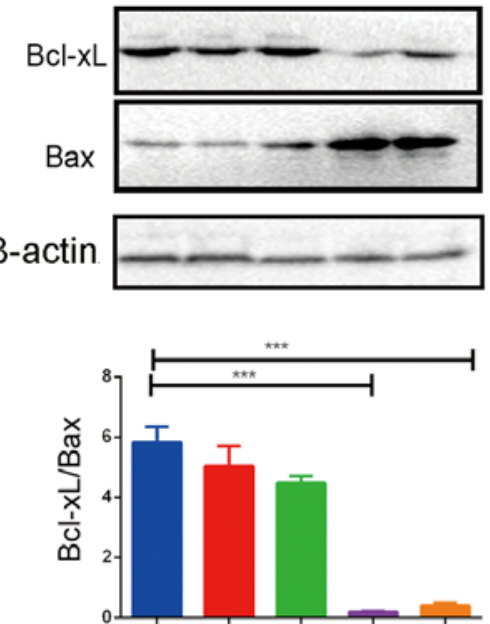

$\operatorname{DOX}(\mu \mathrm{M})-\quad-\quad 4 \quad 4 \quad 4$

si S100A8 - - - - +
C

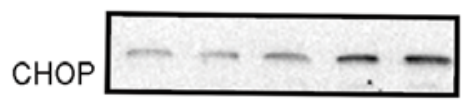

$\beta$-actin ---

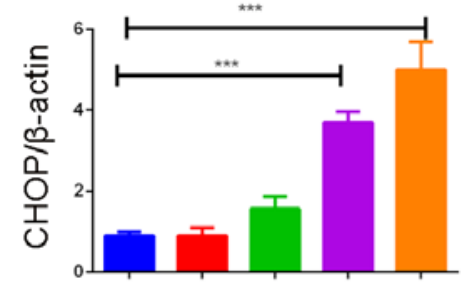

$\operatorname{DOX}(\mu \mathrm{M})-\quad-\quad 4 \quad 4 \quad 4$

si S100A8 - - - - +

Curcumin $(\mu \mathrm{M})-\quad-\quad-\quad 2 \quad 2 \quad$

Curcumin $(\mu \mathrm{M})-2-2-$

Curcumin $(\mu \mathrm{M})-2-2-$

D

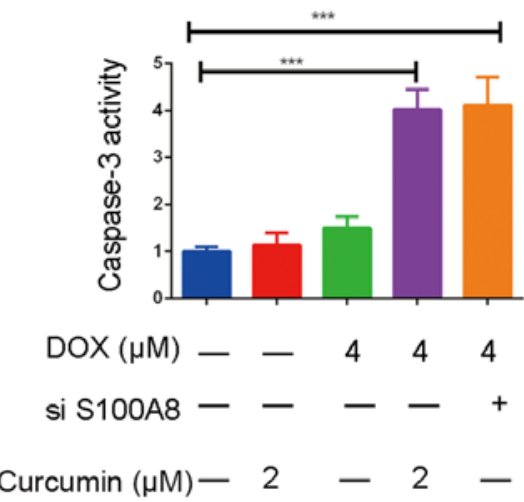

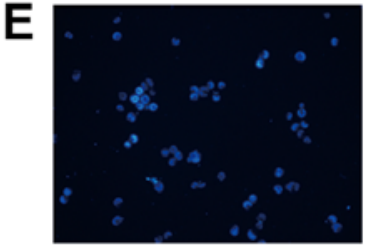

E1: K562/DOX

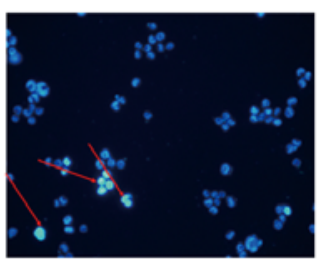

E4:K562/DOX+curcumin

$(2 \mu \mathrm{M})+\mathrm{DOX}(4 \mu \mathrm{M})$

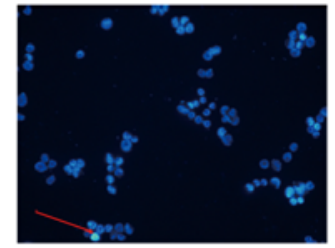

E2: K562/DOX+DOX (4 $\mu \mathrm{M})$

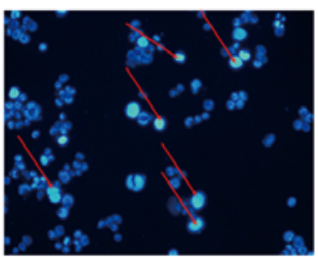

E5:K562/DOX+

si S100A8+DOX $(4 \mu \mathrm{M})$

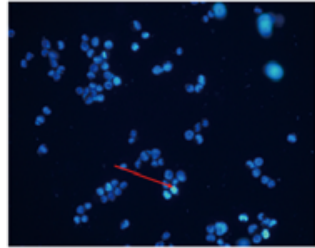

E3:K562/DOX+

curcumin $(2 \mu \mathrm{M})$

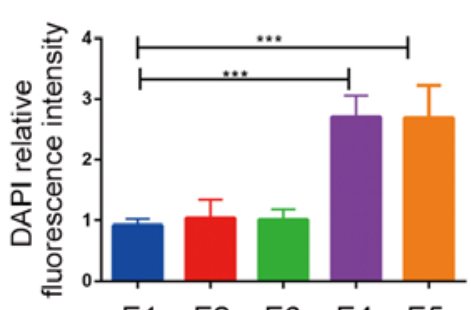

Figure 5. Addition of curcumin enhances apoptosis induced by DOX in K562/DOX cells. (A) Effects of curcumin $(2 \mu \mathrm{M})$, DOX (4 $\mu \mathrm{M})$ and si-S100A8 used alone or in combination on the intracellular free calcium ion concentration in K562/DOX cells. Effects of curcumin $(2 \mu \mathrm{M})$, DOX $(4 \mu \mathrm{M})$ and si-S100A8 used alone or in combination on the protein expression of (B) Bcl-xL, Bax and (C) CHOP in K562/DOX cells. (D) Effects of curcumin ( $2 \mu \mathrm{M})$, DOX (4 $\mu \mathrm{M})$ and si-S100A8 used alone or in combination on caspase-3 activity. (E) K562/DOX cells were stained with DAPI after pre-treatment and observed under an inverted fluorescence microscope (magnification, $\mathrm{x} 40$ ) and the relative fluorescence intensity analysis of DAPI was determined. DNA fragmentation is indicated by red arrows. ${ }^{* * * *} \mathrm{P}<0.001$. DOX, doxorubicin; K562/DOX, DOX-resistant K562 cell line; S100A8, S100 calcium-binding protein A8; Bcl-xL, B-cell lymphoma extra-large; Bax, Bcl-2-associated X protein; CHOP, CCAAT/enhancer-binding protein homologous protein; si-S100A8, small interfering RNA targeting S100A8.

in the intracellular calcium levels (36). To clarify the association between S100A8, calcium ions and the ER, intracellular free calcium ion levels were first examined. The results indicated that the intracellular calcium levels in K562/DOX and $\mathrm{K} 562$ cells were equivalent. After administration of $4 \mu \mathrm{M}$ DOX or $2 \mu \mathrm{M}$ curcumin alone, the intracellular calcium levels did not increase; however, when DOX was combined with curcumin or S100A8 was silenced, the intracellular calcium levels were significantly elevated (Fig. 5A). In addition, the expression of the ERS-associated protein CHOP was increased (Fig. 5C). To investigate the effects on apoptosis, the expression of the apoptosis-associated proteins Bcl-xL and Bax, and the activity of the apoptosis executioner protein caspase-3 were assessed. The results indicated that DOX combined with curcumin or S100A8 silencing significantly decreased the expression of antiapoptotic protein Bcl-xL, whereas the expression of the proapoptotic protein Bax and the activity of caspase- 3 were significantly upregulated (Fig. 5B and D). In addition, the results of a DAPI staining assay revealed that when DOX was combined with curcumin or silencing of S100A8, an increase in nuclear fragmentation was observed, indicative of the occurrence of apoptosis (Fig. 5E). A possible explanation for this observation is that due to the downregulation of S100A8, the increase in intracellular calcium levels induced by the 
chemotherapeutic drug cannot be cleared in time, leading to apoptosis induced by ERS.

\section{Discussion}

The emergence of MDR has seriously impeded the efficacy of chemotherapy for leukemia. Previous studies have indicated that curcumin and its derivatives are capable of reversing the MDR of various types of cancer, including non-small cell lung cancer, liver cancer and colon cancer (37-39). Although the ability of curcumin to reverse drug resistance in solid tumors has been reported in a large number of studies, few studies have examined the reversal of MDR of leukemia by curcumin, and mechanistic investigations mostly focused on the inhibition of P-gp expression (40-43). The aforementioned was confirmed by this study's results. It is well known that P-gp is involved in the development of drug resistance in most cell types, partly due the specific physiological functions of P-gp, and the fact that P-gp has a particularly broad substrate range (44-46). However, it may not be feasible to reverse MDR by inhibiting P-gp alone. The present study revealed that the reversal effects of curcumin are not only associated with P-gp, but also with the inhibition of S100A8 expression. To the best of our knowledge, S100A8 has not been reported prior to this study as a target of curcumin.

To investigate the underlying mechanisms, the present study examined two proteins, P-gp and S100A8, and aimed to identify an association between the two. First, the effects of curcumin on the expression of S100A8 and P-gp were investigated. The results suggested that curcumin decreased the expression of P-gp and S100A8 in a time- and dose-dependent manner.

The ability of curcumin to reverse resistance and downregulate S100A8 expression after administration was observed. To demonstrate that S100A8 downregulation was associated with the reverse of drug-resistance, S100A8 gene silencing was performed using siRNAs inhibiting S100A8 expression. The results showed that after inhibiting S100A8 expression, drug-resistant cells were more sensitive to DOX, the expression and activity of proapoptotic proteins was increased, and the ratio of Bcl-xl and Bax was decreased. The results indicated that the alterations in S100A8 expression level were important for the reversal of drug resistance. To identify the potential association between P-gp and S100A8, the expression of each was separately inhibited by gene silencing, with the expression of the other protein then evaluated. The results indicated that the two proteins did not directly regulate the expression of the alternate protein; therefore, curcumin may act independently on them.

The molecular mechanisms via which curcumin acted on P-gp and S100A8 individually were subsequently examined. K562/DOX cells overexpress of P-gp and S100A8 compared with K562 cells. Curcumin did not affect DOX sensitivity in the K562 model, likely due to low expression of P-gp and S100A8. For P-gp, in order to investigate the effect of curcumin on its transport function, curcumin and RHO-123 were applied to K562/DOX cells simultaneously. Following incubation for $45 \mathrm{~min}$, the intracellular RHO-123 levels were detected, with the P-gp-specific inhibitor VRP used as a positive control $(47,48)$. The results suggested that when curcumin was applied to K562/DOX cells, the intracellular accumulation of RHO-123 increased significantly, indicating that curcumin inhibited the function of P-gp.

For the calcium ion-binding protein S100A8, the results indicated that the downregulation of S100A8 by curcumin may enhance ERS induced by DOX and thereby increase cell apoptosis. Calcium ions have an important role in intracellular signal transduction (49). They are able to activate a variety of different protein kinases involved in various biological processes, including cell proliferation, differentiation, invasion and apoptosis $(50,51)$. The ER is the major site for intracellular protein synthesis, secretion, modification and transport, and is also the major organelle for the maintenance of the intracellular calcium balance (52). Under physiological conditions, the levels of free calcium ions in the cytoplasm are much lower than those in the ER (53). The calcium ion pump moves calcium ions from the cytosol into the ER, whereas the ER releases calcium ions from the cytosol via ryanodine receptors and inositol 1,4,5-trisphosphate receptors to maintain the homeostasis of intracellular calcium ions (54-56). An increase in the levels of intracellular free calcium ions causes an imbalance of intracellular calcium ion homeostasis that leads to calcium overload in the ER, resulting in ERS and the induction of apoptosis (54-56). In the present study, changes in intracellular calcium in K562/DOX cells were examined. It was revealed that, while $4 \mu \mathrm{M}$ DOX did not significantly change intracellular calcium levels, they were significantly increased when DOX was combined with curcumin or S100A8 siRNA transfection.

CHOP is a specific transcription factor for ERS. When ERS induces apoptosis, the expression of CHOP is notably increased and the protein accumulates in the nucleus, where it induces apoptosis. In addition, CHOP also affects the expression of Bcl-2 family proteins; specifically, it inhibits the expression of the antiapoptotic $\mathrm{Bcl}$ protein and increases the sensitivity of mitochondria to proapoptotic factors (57). The results of the present study suggested that the combination of DOX and curcumin or silencing of S100A8 causes an upregulation of CHOP expression, a downregulation of the $\mathrm{Bcl}-\mathrm{xL} / \mathrm{Bax}$ ratio and an increase in caspase activity, which is expected to be associated with marked ERS and cell apoptosis. In addition, to evaluate cell death, nuclear staining with DAPI was performed. It was revealed that in the DOX + curcumin and the DOX + S100A8 siRNA groups, a significant increase in nuclear fragmentation was present, suggesting that apoptosis occurred. It's worth mentioning that when designing the assays, the drug to treat K562 as a control was not designed by the present study. There were two reasons for this: The concentration of DOX $(4 \mu \mathrm{M})$ far exceeds the $\mathrm{IC}_{50}(1.38 \mu \mathrm{M})$ value of K562 for DOX, which inevitably causes a large number of cell deaths, and for K562/DOX cells, the concentration of $4 \mu \mathrm{M}$ is much lower than its $\mathrm{IC}_{50}(13.83 \mu \mathrm{M})$ value, due to drug resistance (Fig. 1B; Table I).

In conclusion, the present study indicated that curcumin reversed the resistance of K562/DOX cells to DOX, and S100A8 and P-gp were identified as two independent targets. Curcumin was demonstrated to inhibit the expression and function of P-gp, and to increase the intracellular accumulation of DOX. Furthermore, curcumin downregulated the expression 
of S100A8, causing an intracellular calcium ion imbalance that resulted in increased ERS, thereby accelerating cell apoptosis.

\section{Acknowledgements}

Not applicable.

\section{Funding}

No funding was received.

\section{Availability of data and materials}

The datasets used and/or analyzed during the current study are available from the corresponding author on reasonable request.

\section{Authors' contributions}

LY completed the major assays such as RNA knockdown, western blot analysis and flow cytometry. DL analyzed the data and was responsible for the cell culture. LY and DL contributed to the writing of this manuscript, while PT and YZ contributed the conception and design of the study, and editing of the manuscript. All authors have read and approved the final version of this manuscript.

\section{Ethics approval and consent to participate}

Not applicable.

\section{Patient consent for publication}

Not applicable.

\section{Competing interests}

The authors declare that there are no competing interests.

\section{References}

1. Swerdlow S, Campo E, Harris N, Jaffe E, Pileri S, Stein H, Thiele $\mathrm{J}$ and Vardiman $\mathrm{J}$ : WHO Classification of Tumours of Haematopoietic and Lymphoid Tissues. IARC, Lyon, 2008.

2. Agrawal M, Hanfstein B, Erben P, Wolf D, Ernst T, Fabarius A, Saussele S, Purkayastha D, Woodman RC, Hofmann WK, et al: MDR1 expression predicts outcome of $\mathrm{Ph}+$ chronic phase CML patients on second-line nilotinib therapy after imatinib failure. Leukemia 28: 1478-1485, 2014.

3. Zhang Q, Feng Y and Kennedy D: Multidrug-resistant cancer cells and cancer stem cells hijack cellular systems to circumvent systemic therapies, can natural products reverse this? Cell Mol Life Sci 74: 777-801, 2017.

4. Xia CQ and Smith PG: Drug efflux transporters and multidrug resistance in acute leukemia: Therapeutic impact and novel approaches to mediation. Mol Pharmacol 82: 1008-1021, 2012.

5. Briot T, Roger E, Thépot S and Lagarce F: Advances in treatment formulations for acute myeloid leukemia. Drug Discov. Today 23 1936-1949, 2018.

6. Salerno L, Romeo G, Modica MN, Amata E, Sorrenti V, Barbagallo I and Pittalà V: Heme oxygenase-1: A new druggable target in the management of chronic and acute myeloid leukemia. Eur J Med Chem 142: 163-178, 2017.

7. Tsuruo T, Iida H, Tsukagoshi S and Sakurai Y: Overcoming of vincristine resistance in P388 leukemia in vivo and in vitrothrough enhanced cytotoxicity of vincristine and vinblastine by verapamil. Cancer Res 41: 1967-1972, 1981.
8. Batra P and Sharma AK: Anti-cancer potential of flavonoids: Recent trends and future perspectives. 3 Biotech 3: 439-459, 2013.

9. Jacquemin G, Granci V, Gallouet AS, Lalaoui N, Morlé A, Iessi E, Morizot A, Garrido C, Guillaudeux T and Micheau O: Quercetin-mediated Mcl-1 and survivin downregulation restores TRAIL-induced apoptosis in non-Hodgkin's lymphoma B cells. Haematologica 97: 38-46, 2012.

10. Goel A, Kunnumakkara AB and Aggarwal BB: Curcumin as 'Curecumin': From kitchen to clinic. Biochem Pharmacol 75: 787-809, 2008.

11. Ravindran J, Prasad S and Aggarwal BB: Curcumin and cancer cells: How many ways can curry Kill tumor cells selectively? AAPS J 11: 495-510, 2009.

12. Banerjee S, Ji C, Mayfield JE, Goel A, Xiao J, Dixon JE and Guo X: Ancient drug curcumin impedes 26S proteasome activity by direct inhibition of dual-specificity tyrosine-regulated kinase 2. Proc Natl Acad Sci USA 115: 8155-8160, 2018.

13. Romiti N, Tongiani R, Cervelli F and Chieli E: Effects of curcumin on P-glycoprotein in primary cultures of rat hepatocytes. Life Sci 62: 2349-2358, 1998.

14. Gu Y, Li J, Li Y, Song L, Li D, Peng L, Wan Y and Hua S: Nanomicelles loaded with doxorubicin and curcumin for alleviating multidrug resistance in lung cancer. Int J Nanomedicine 11: 5757-5770, 2016.

15. Mapoung S, Pitchakarn P, Yodkeeree S, Ovatlarnporn C, Sakorn N and Limtrakul P: Chemosensitizing effects of synthetic curcumin analogs on human multi-drug resistance leukemic cells. Chem Biol Interact 244: 140-148, 2016.

16. Maia RC, Vasconcelos FC, Souza PS and Rumjanek VM: Towards Comprehension of the ABCB1/P-glycoprotein role in chronic myeloid leukemia. Molecules 23: pii: E119, 2018.

17. Lalioti VS, Ilari A, O'Connell DJ, Poser E, Sandoval IV and Colotti G: Sorcin links calcium signaling to vesicle trafficking, regulates Polo-like kinase 1 and is necessary for mitosis. PLoS One 9: e85438, 2014.

18. Bresnick AR, Weber DJ and Zimmer DB: S100 proteins in cancer. Nat Rev Cancer 15: 96-109, 2015.

19. Salama I, Malone PS, Mihaimeed F and Jones JL: A review of the S100 proteins in cancer. Eur J Surg Oncol 34: 357-364, 2008.

20. Nicolas E, Ramus C, Berthier S, Arlotto M, Bouamrani A, Lefebvre C, Morel F, Garin J, Ifrah N, Berger F, et al: Expression of S100A8 in leukemic cells predicts poor survival in de novo AML patients. Leukemia 25: 57-65, 2011.

21. Spijkers-Hagelstein JA, Schneider P, Hulleman E, de Boer J, Williams O, Pieters R and Stam RW: Elevated S100A8/S100A9 expression causes glucocorticoid resistance in MLL-rearranged infant acute lymphoblastic leukemia. Leukemia 26: 1255-1265, 2012.

22. Yang XY, Zhang MY, Zhou Q, Wu SY, Zhao Y, Gu WY, Pan J, Cen JN, Chen ZX, Guo WG, et al: High expression of S100A8 gene is associated with drug resistance to etoposide and poor prognosis in acute myeloid leukemia through influencing the apoptosis pathway. Onco Targets Ther 9: 4887-4899, 2016.

23. Yang M, Zeng P, Kang R, Yu Y, Yang L, Tang D and Cao L: S100A8 contributes to drug resistance by promoting autophagy in leukemia cells. PLoS One 9: e97242, 2014.

24. Lampidis TJ, Shi YF, Calderon CL, Kolonias D, Tapiero H and Savaraj N: Accumulation of simple organic cations correlates with differential cytotoxicity in multidrug-resistant and -sensitive human and rodent cells. Leukemia 11: 1156-1159, 1997.

25. Liu Y, Zhang SP and Cai YQ: Cytoprotective effects of selenium on cadmium-induced LLC-PK1 cells apoptosis by activating JNK pathway. Toxicol In Vitro 21: 677-684, 2007.

26. Zhou H, Qian J, Wang J, Yao W, Liu C, Chen J and Cao X: Enhanced bioactivity of bone morphogenetic protein-2 with low dose of 2-N, 6-O-sulfated chitosan in vitro and in vivo. Biomaterials 30: 1715-1724, 2009.

27. Kapuscinski J: DAPI: A DNA-specific fluorescent probe. Biotech Histochem 70: 220-233, 1995.

28. Yan P, Li T, Bo M, Die L and Xing L: Inhibition of bone resorption by econazole in rat osteoclast-like cells through suppressing TRPV5. Arch Pharm Res 34: 1007-1013, 2011

29. Yhee JY, Song S, Lee SJ, Park SG, Kim KS, Kim MG, Son S, Koo H, Kwon IC, Jeong JH, et al: Cancer-targeted MDR-1 siRNA delivery using self-cross-linked glycol chitosan nanoparticles to overcome drug resistance. J Control Release 198: 1-9, 2015.

30. Yan LL, Huang YJ, Yi X, Yan XM, Cai Y, He Q and Han ZJ: Effects of silencing S100A8 and S100A9 with small interfering RNA on the migration of CNE1 nasopharyngeal carcinoma cells. Oncol Lett 9: 2534-2540, 2015. 
31. Morsy MA, El-Sheikh AAK, Ibrahim ARN, Khedr MA and Al-Taher AY: In silico comparisons between natural inhibitors of $\mathrm{ABCB} 1 / \mathrm{P}-\mathrm{glycoprotein}$ to overcome doxorubicin-resistance in the NCI/ADR-RES cell line. Eur J Pharm Sci 112: 87-94, 2018.

32. Fletcher JI, Williams RT, Henderson MJ, Norris MD and Haber M: $\mathrm{ABC}$ transporters as mediators of drug resistance and contributors to cancer cell biology. Drug Resist Updat 26: 1-9, 2016.

33. Servili E, Trus M, Maayan D and Atlas D: $\beta$-Subunit of the voltage-gated $\mathrm{Ca} 2+$ channel Cav1.2 drives signaling to the nucleus via H-Ras. Proc Natl Acad Sci USA 115: E8624-E8633, 2018.

34. DeCaen PG, Delling M, Vien TN and Clapham DE: Direct recording and molecular identification of the calcium channel of primary cilia. Nature 504: 315-318, 2013.

35. Monteith GR, Prevarskaya N and Roberts-Thomson SJ: The calcium-cancer signalling nexus. Nat Rev Cancer 17: 367-380, 2017.

36. Hajnóczky G, Booth D, Csordás G, Debattisti V, Golenár T, Naghdi S, Niknejad N, Paillard M, Seifert EL and Weaver D: Reliance of ER-mitochondrial calcium signaling on mitochondrial EF-hand Ca 2+ binding proteins: Miros, MICUs, LETM1 and solute carriers. Curr Opin Cell Biol 29: 133-141, 2014.

37. Andjelkovic T, Pesic M, Bankovic J, Tanic N, Markovic ID and Ruzdijic S: Synergistic effects of the purine analog sulfinosine and curcumin on the multidrug resistant human non-small cell lung carcinoma cell line (NCI-H460/R). Cancer Biol Ther 7 : 1024-1032, 2008.

38. Chiu LY, Ko JL, Lee YJ, Yang TY, Tee YT and Sheu GT: L-type calcium channel blockers reverse docetaxel and vincristine-induced multidrug resistance independent of ABCB1 expression in human lung cancer cell lines. Toxicol Lett 192: 408-418, 2010

39. Prasad N, Sudhakar YA and Kanwar JR: Curcumin regulates colon cancer by inhibiting P-Glycoprotein in In-situ Cancerous colon perfusion rat model. J Cancer Sci Ther 5: 313-319, 2013.

40. Shah K, Mirza S, Desai U, Jain N and Rawal R: Synergism of curcumin and cytarabine in the down regulation of Multi-Drug resistance genes in acute myeloid leukemia. Anticancer Agents Med Chem 16: 128-135, 2016.

41. Misra R and Sahoo SK: Coformulation of doxorubicin and curcumin in poly(D,L-lactide-co-glycolide) nanoparticles suppresses the development of multidrug resistance in K562 cells. Mol Pharm 8: 852-866, 2011.

42. Anuchapreeda S, Thanarattanakorn P, Sittipreechacharn S, Tima S, Chanarat P and Limtrakul P: Inhibitory effect of curcumin on MDR1 gene expression in patient leukemic cells. Arch Pharm Res 29: 866-873, 2006.

43. Choi BH, Kim CG, Lim Y, Shin SY and Lee YH: Curcumin down-regulates the multidrug-resistance mdrlb gene by inhibiting the PI3K/Akt/NF kappa B pathway. Cancer Lett 259: 111-118, 2008.

44. Robey RW, Pluchino KM, Hall MD, Fojo AT, Bates SE and Gottesman MM: Revisiting the role of ABC transporters in multidrug-resistant cancer. Nat Rev Cancer 18: 452-464, 2018.
45. Yang SS, Liu AL, Shan LL, Zeng TC, Zhou Q and Li YB: Pharmacokinetics mechanism of ABC efflux proteins-mediated seven features of compatibility. Zhongguo Zhong Yao Za Zhi 43: 676-683, 2018 (In Chinese).

46. Efferth T and Volm M: Multiple resistance to carcinogens and xenobiotics: P-glycoproteins as universal detoxifiers. Arch Toxicol 91: 2515-2538, 2017.

47. Huang J, Guo L, Tan R, Wei M, Zhang J, Zhao Y, Gong L, Huang $Z$ and Qiu X: Interactions between emodin and efflux transporters on rat enterocyte by a validated ussing chamber technique. Front Pharmacol 9: 646, 2018.

48. Ampasavate $\mathrm{C}$, Sotanaphun U, Phattanawasin $\mathrm{P}$ and Piyapolrungroj N: Effects of curcuma spp. on P-glycoprotein function. Phytomedicine 17: 506-512, 2010.

49. Monteith GR, Prevarskaya N and Roberts-Thomson SJ: The calcium-cancer signalling nexus. Nat Rev Cancer 17: 367-380, 2017.

50. Kania E, Roest G, Vervliet T, Parys JB and Bultynck G: IP3Receptor-mediated calcium signaling and its role in autophagy in cancer. Front Oncol 7: 140, 2017.

51. Dubois C, Vanden Abeele F and Prevarskaya N: Targeting apoptosis by the remodelling of calcium-transporting proteins in cancerogenesis. FEBS J 280: 5500-5510, 2013.

52. Roderick HL and Bootman MD: Redoxing calcium from the ER. Cell 120: 4-5, 2005.

53. Clapham DE: Calcium signaling. Cell 131: 1047-1058, 2007.

54. Luciani DS, Gwiazda KS, Yang TL, Kalynyak TB, Bychkivska Y, Frey MH, Jeffrey KD, Sampaio AV, Underhill TM and Johnson JD: Roles of IP3R and RyR Ca2+Channels in endoplasmic reticulum stress and $\beta$-cell death. Diabetes 58: 422-432, 2009.

55. Dubois C, Vanden Abeele F, Sehgal P, Olesen C, Junker S, Christensen SB, Prevarskaya N and Møller JV: Differential effects of thapsigargin analogues on apoptosis of prostate cancer cells: Complex regulation by intracellular calcium. FEBS J 280: 5430-5440, 2013

56. Ansari N, Hadi-Alijanvand $\mathrm{H}$, Sabbaghian $\mathrm{M}$, Kiaei $\mathrm{M}$ and Khodagholi F: Interaction of 2-APB, dantrolene, and TDMT with IP3R and RyR modulates ER stress-induced programmed cell death I and II in neuron-like PC12 cells: An experimental and computational investigation. J Biomol Struct Dyn 32: 1211-1230, 2014.

57. Bouman L, Schlierf A, Lutz AK, Shan J, Deinlein A, Kast J, Galehdar Z, Palmisano V, Patenge N, Berg D, et al: Parkin is transcriptionally regulated by ATF4: Evidence for an interconnection between mitochondrial stress and ER stress. Cell Death Differ 18: 769-782, 2011.

This work is licensed under a Creative Commons Attribution-NonCommercial-NoDerivatives 4.0 International (CC BY-NC-ND 4.0) License. 